\title{
Da subjetividade na linguagem fotográfica: as categorias de pessoa e não-pessoa na narração de si
}

\author{
Paula Ávila Nunes ${ }^{1}$ \\ Programa de Pós-graduação em Estudos de Linguagens (PPGEL), \\ Universidade Tecnológica Federal do Paraná (UTFPR), Curitiba, PR, Brasil
}

Resumo: Este trabalho interroga-se quanto ao lugar da linguagem fotográfica no contexto da economia das trocas simbólicas no cenário contemporâneo, acentuadamente marcada pela presença de imagens (notadamente autorretratos) postadas, compartilhadas e comentadas em redes sociais. Entende-se, com Benveniste (1989; 1995), que a mobilização de diferentes sistemas semióticos para construção de um sentido nunca tem um mesmo efeito, tendo em vista que não há sobreposição de sistemas e que o sistema da língua é o principal entre todas as formas simbólicas humanas. Assim, se o sujeito contemporâneo tem sua subjetividade expressa fortemente por meio do recurso a uma linguagem de base representacional mais icônica, temos o que parece ser uma enunciação sem diálogo, pois que esvazia o caráter de alteridade ao tornar o "eu", pessoa que enuncia, em um "ele", não-pessoa (BENVENISTE, 1995), em virtude do caráter de exposição apontado por Han (2017).

Palavras-chave: Fotografia; Linguística da Enunciação; Subjetividade.

Title: On the subjectivity of photographic language: the categories of person and non-person in the narration of oneself

Abstract: This article questions the place of photographic language in the context of the economy of symbolical exchanges in the contemporary scenario, notably marked by the presence of images (especially selfies) posted, shared and commented on social medias. With Benveniste (1989; 1995), we understand that the use of different semiotic systems in meaning production has never the same effect, bearing in mind there is no such thing as a system overlap and that the main system among human's symbolical forms is always that of language. Therefore, if the contemporary subject strongly expresses his subjectivity through the resource to a more iconic language, we have what appears to be an utterance with no dialogue, as it is deprived from its character of alterity when the "l", the person who enunciates, becomes a "he", non-person (BENVENISTE, 1995), due to the aspect of exposition pointed out by Han (2017)

Keywords: Photography; Enunciative studies; Subjectivity.

\footnotetext{
${ }^{1}$ Doutora em Letras pela Universidade Federal do Rio Grande do Sul. Professora adjunta do curso de Letras da Universidade Tecnológica Federal do Paraná e do Programa de Pós-graduação em Estudos de linguagens. Orcid: https://orcid.org/0000-0002-9696-0625. E-mail: paulanunes@utfpr.edu.br
} 
Em 2018, um usuário qualquer, entre tantos, da plataforma de compartilhamento de vídeos chamada Vimeo publicou uma compilação de fotos justapostas, dando a elas formato de vídeo, à qual deu o nome de "Instatravel: uma experiência fotogênica de turismo de massa". . As mais de 1 milhão e 200 mil visualizações mostram o engajamento dos usuários da plataforma, que também hospeda outras versões de mesma inspiração temática: a reprodutibilidade (técnica) aparentemente infinita dos (hoje literalmente) instantâneos de viagem, disparados sempre sob um mesmo ângulo, capturando frequentemente as mesmas poses, enquanto um monumento ou obra de arte (ou ambos) repousa inalteradamente como pano de fundo, ocupando lugar central.

A crítica sugerida é óbvia: nossas memórias de viagem, eternizadas em formato fotográfico, estão, talvez, ficando mais repetitivas e dispondo de menos criatividade. De um lado, talvez isso tenha sempre acontecido, e a impossibilidade de compartilhamento massivo do material tenha nos impedido de observar tal fenômeno. De outro, é também possível que a própria divulgação de fotografias pessoais - hoje tão amplamente difundidas, mas antes enclausuradas nos álbuns fotográficos e compartilhadas somente em ocasiões específicas, acompanhadas de uma narração daquele que mostrava suas recordações íntimas - tenha criado certas gramáticas específicas de reprodução de imagens e, por consequência, alterado alguns aspectos de nossa narração sobre os eventos que tencionamos arquivar nas películas agora virtuais.

Independentemente de nossas hipóteses, fato é que a evolução tecnológica, como nos mostra, por exemplo, Poe (2011), continua alavancando transformações em nossas formas de comunicar, compreender e se expressar. Tem-se aí, portanto, um ponto de toque bastante sensível entre linguagem e tecnologia, que reclama atenção. Nessa dinâmica, este texto se debruça sobre um aspecto bastante circunscrito dessa relação, a saber: a incorporação de tecnologias na economia das trocas simbólicas. Mais especificamente, dado que esse assunto certamente carrega pouco ineditismo, propomo-nos a pensar como a apropriação de duas tecnologias, a Internet e a câmera digital embutida no smartphone, estejam possivelmente promovendo novas formas de subjetivação, se entendermos "subjetivação" 3 em consonância ao que Paula Sibilia (2016) chama de conjunto de "formas de ser e estar no mundo".

Com isso em mente, intentamos observar de que maneira essas linguagens ${ }^{4}$, verbal e

\footnotetext{
${ }^{2}$ Acessível pelo link https://vimeo.com/253334732. Acesso em: 02 ago. 2020.

3 "Dessubjetivação", no entanto, encontrado mais à frente neste escrito, não se refere a uma não existência simbólica no mundo, o que seria evidentemente impossível, mas a uma conceituação muito específica, circunscrita à ótica de contemplação da linguagem a partir de Émile Benveniste (1995; 1989): dessubjetivar é eliminar os traços linguístico-enunciativos de eu, pessoa que fala, base do paradigma da subjetividade, com todas as implicações que isso tem, conforme veremos adiante.

${ }^{4}$ A referência à fotografia (ou a outros sistemas semiológicos) como uma "linguagem" não é, certamente, unanimidade, tendo sido, inclusive, alvo de reflexão por parte de especialistas - ver, por exemplo, as considerações que Stam (2003) tece sobre as correlações do sistema audiovisual com a noção de linguagem. Há quem possa questionar a legitimidade de se atribuir a outros sistemas semiológicos quaisquer características de uma linguagem. Saussure (2005) e Benveniste (1989; 1995), por exemplo, referem-se a isso que estou chamando de "outras linguagens" como sistemas semióticos, sistemas de signos ou sistemas semiológicos. Embora entendamos suas motivações, acreditamos que tais pormenores teminológicos, embora motivados e objetos
} 
fotográfica, ao serem mobilizadas - às vezes isolada, outras vezes concomitantemente -, comunicam diferentes formas de ser e estar no mundo, e, por conseguinte, distintas maneiras de narração de si. Fazemos essa apreciação pautados no fato de que, embora tenhamos sempre recorrido a sistemas de bases semióticas dessemelhantes, há um custo mobilizar um sistema semiológico ou outro, pois, parafraseando Benveniste (1989), nenhuma linguagem pode expressar exatamente a mesma relação de sentido que outra, o que ganha contornos mais visíveis quando se trata de semioses distintas, pois a relação de sentido (arbitrária ${ }^{5}$, para a língua, e icônica ${ }^{6}$, para a fotografia) impede equiparações exatas. Interessa-nos, nesse contexto, investigar como essa economia comunicativa tem afetado as trocas linguísticas. Trata-se de "trocas", efetivamente, pois o objeto de investigação é justamente a aparente "troca" que tem sido feita, sobretudo em redes sociais, da linguagem duplamente articulada (língua) pela linguagem fotográfica, com o propósito de falar de si.

O sujeito contemporâneo, conjectura-se, tem-se dedicado a dar sentido a suas vivências a partir de um mecanismo que apenas a apropriação tecnológica da câmera digital, alocada no smartphone, o permitiu exercer: narrar a si mesmo a partir de fotografias, ou seja por meio de narrativas visuais ${ }^{7}$, criando, assim, uma forma particularmente contemporânea

prospectivos de investigação, não têm espaço neste escrito, dada a grande envergadura do assunto. Optamos, assim, pelo "abuso dos termos", como diria Benveniste, e chamamos de "linguagem", para fins desta exposição, qualquer sistema semiológico.

${ }^{5}$ Embora não mobilizemos o escopo teórico da semiótica peirceana, o próprio Benveniste, autor em que nos ancoramos, elabora um de seus ensaios mais importantes para a digressão que fazemos aqui (Semiologia da língua, 1969) partindo do estudo do "edifício teórico" do pensador americano, motivo pelo qual não entendemos que seja uma inadequação metodológica em recorrer a essa nomenclatura, tão conhecida, como recurso de distinção entre as duas linguagens em pauta.

${ }^{6}$ De forma bastante resumida e até simplista, Charles Sanders Peirce, em seu artigo What is a sign?, de 1894, discorre sobre a natureza dos processos de formação do significado na mente humana (isto é, sobre o vínculo entre o interpretante, o representâmen e o objeto, conforme nomenclatura empregada pelo teórico), distinguindo as diferentes formas de representação mobilizadas por cada tipo de signo em um quadro conceitual, que resta conhecido até hoje. Embora, para Peirce, o referente seja um conceito relevante - que o leva, inclusive, a pensar em um triângulo semiótico entre os três termos supracitados, ideia completamente rechaçada por um pensamento tributário de Benveniste e, consequentemente, de Saussure, tal como o desenvolvido aqui -, acreditamos que a tripartição proposta pelo americano, ainda que fortemente criticada por Benveniste em Semiologia da língua, pode ser-nos útil para os propósitos deste texto. Para os não familiarizados com a nomenclatura, para Peirce, há três tipos de signos, classificados de acordo com sua forma de representação do referente denotado: (1) ícones, que mantêm relação de semelhança (likeness) com o objeto denotado, como acontece no caso da fotografia; (2) índices, cuja relação com o referente é de indicação (indication), ou seja, uma relação de indício; e (3) símbolos, dominados por uma relação de convenção (convention) com o que denotam. Neste último grupo, encontram-se os signos linguísticos, ainda que, como já dito, na tradição dos estudos herdeiros da concepção saussuriana de língua, exclua-se a ideia de referente no mundo e passe-se a tratar a convencionalidade como arbitrariedade (ver, sobre isso, o texto Natureza do signo linguístico, de Benveniste, escrito em 1939, e publicado em Problemas de Linguística Geral I, conforme bibliografia).

7 O conceito de "narrativa" é, certamente, conhecido no campo dos estudos da linguagem, sobretudo pelas teorizações feitas no campo da literatura. Uma "narrativa visual", entretanto, talvez não seja um termo tão transparente para o leitor. Com ele, aludimos (embora possa haver outras definições e interpretações do termo) àquilo que Sergei Eisenstein, cineasta soviético, chamou, em seu livro A forma do filme, de "montagem". Para ele, se transpusermos seu raciocínio para nosso objeto aqui, a justaposição de duas imagens, por exemplo, mesmo que cada uma represente um sentido isoladamente, ganha um terceiro (ou vários outros) sentido(s) pela justaposição, ou seja, pela edição. Essa montagem, no âmbito técnico, produz também uma montagem em nível intelectual, posto que a interpretação da justaposição como algo diferente da interpretação de cada imagem 
de ser e estar no mundo (SIBILIA, 2016). Do ponto de vista da linguística de base enunciativa, esteio teórico principal em que repousa este texto, temos uma configuração comunicativa muito particular, que nos leva à questão que tentamos responder aqui: o que acontece quando o sujeito mobiliza linguagens de relação representacional (entre significante e significado) mais icônica, como a fotografia, em detrimento de linguagens de relação representacional mais arbitrária, como a língua? Tal questionamento decorre da constatação de que redes sociais, tais como Facebook e Instagram, ao proporcionarem a oportunidade de upload de fotografias para as páginas pessoais dos usuários, têm levado grande número de pessoas a significarem suas existências (cf. infra) por meio do recurso ao visual, deixando o elemento linguístico stricto sensu, isto é, a língua, muitas vezes em segundo plano.

Evidentemente, reconhecemos que o próprio recurso à fotografia - inserida numa cena enunciativa específica, instaurada pelas plataformas de compartilhamento - cria todo um contexto de veiculação e de interpretação dessa mensagem. Entretanto, o ponto de vista que se propõe aqui não é aquele de entender essas dinâmicas comunicacionais como destituídas de sentido, mas de ressaltar o fato de que compõem um outro sentido, diferente do que pode ser expresso linguisticamente. Assim, o intuito é de observar especificamente os efeitos que a proliferação de imagens, tornada possível por determinados recursos tecnológicos, imprimiu sobre as narrativas (visuais) que o sujeito faz de si.

Nessa conjuntura, ao tentarmos responder o que muda quando a linguagem mobilizada é outra, partimos de dois pressupostos básicos. O primeiro deles se assenta nas reflexões de Cassirer (2012), para quem o ser humano é, antes de tudo, um animal symbolicus, dotado de diversas formas simbólicas (tais como a linguagem, o mito, a ciência, a arte, a religião etc.) que o auxiliam na difícil incumbência de dar sentido ao mundo e a si mesmo. Assim, nada mais natural que o homem recorra a diferentes linguagens nessa tarefa, uma vez que sistemas semiológicos não linguísticos parecem existir justamente para, de alguma forma, produzir sentidos que escapam ao que a língua se permite comunicar. Em outras palavras, poderíamos dizer que o que essas formas simbólicas comportam é aquilo que escapa ao dizível do plano linguístico, que não pode ser simbolizado em palavras, o que Wittgenstein (2008) já evidenciava ao elaborar que há algo inexprimível pela língua; assim, para este filósofo, aquilo que pode ser mostrado não pode ser dito e o que é dito não pode ser mostrado, pois cada linguagem opera com formas específicas de produzir sentidos (em nossa problemática aqui, mostrando, para a fotografia, evocando e nomeando, para a língua).

Enfatizemos, mais uma vez, para que não reste dúvidas: todas essas formas simbólicas significam, mas não da mesma maneira. Aparentemente óbvia, essa afirmação encerra uma apreciação sobre o fenômeno do sentido que pode passar despercebida: os sistemas linguageiros ${ }^{8}$ não se recobrem. Para usar os termos benvenisteanos, diríamos que é possível

isoladamente é uma criação mental que se dá pela experiência do sujeito com as noções de análise e síntese, propiciadas por nossa experiência de mundo. Além disso, é importante salientar que, malgrado o que o adjetivo "visual" possa levar-nos a entender, a narrativa visual é frequentemente entendida como aquela que mobiliza linguagem verbal e não verbal.

${ }^{8}$ Usamos, neste texto, o termo "linguístico" para nos referirmos a uma adjetivação relacionada ao sistema da 
uma relação de homologia9 entre sistemas, mas que "o homem não dispõe de vários sistemas distintos para a MESMA relação de significação" (1989, p. 54, maiúsculas no original). Além disso, acrescenta Benveniste, não só não é possível "dizer a mesma coisa" pela língua e por outro sistema, como também a língua é o principal sistema semiológico, dotado de uma capacidade única: a de interpretância de outros sistemas, inclusive dela mesma (pela função metalinguística, ou pelo que o autor chama de relação de interpretância).

Tais pressupostos se ligam ao raciocínio que empreendemos aqui da seguinte maneira: se é natural ao ser humano recorrer a diferentes formas simbólicas para interpretar a si mesmo e ao mundo, nada mais natural do que o fenômeno contemporâneo de dar sentido a nossas vivências também por meio de narrativas visuais. Entretanto, como bem lembra Benveniste, se transpormos seu pensamento para o conjunto de questões que elaboramos aqui, o recurso a um sistema não linguístico tem um custo, uma vez que institui um processo de produção e interpretação de sentidos que difere do que se passa quando o enquadramento ${ }^{10}$ de sentido se dá pela língua. Assim, a pergunta que nos norteia é: se o sentido literalmente se transforma, isto é, adquire outra forma (semiológica), o que muda quando recorremos a uma imagem no lugar de uma palavra? Nossas respostas caminham em duas direções: do ponto de vista da Linguística, nossa hipótese é que a fotografia casual, a que passaremos a chamar aqui de fotografia transparente (HAN, 2017, conforme definido adiante), sobretudo o autorretrato (selfie), é uma enunciação em que aquele que produz o enunciado (nesse caso, a imagem) se coloca tanto na posição de $e u$, ao efetivamente acionar o botão que cria a foto (ou seja, na enunciação ${ }^{11}$ ), quanto de ele, ao aparecer na foto (ou seja, no enunciado). Tendo em vista que o que "sobra" desse processo é, muitas vezes, apenas a publicação da imagem, tem-se, então, nesse contexto específico, a redução de um eu a um ele. Com isso, temos um movimento de passagem de pessoa para não-pessoa (BENVENISTE, 1989; 1995), conforme desenvolvido adiante. Disso, deriva-se, então, uma resposta que tem implicações sociológicas, antropológicas, psicológicas e filosóficas: se o sujeito passa de eu, pessoa, para ele, não-pessoa, temos, portanto, o que muitos teóricos, de diferentes formas, chamam de um efeito de dessubjetivação.

De nossa parte, tentamos argumentar, nas páginas que seguem, que o excesso de exposição por meio da grande quantidade de fotografias circulantes nas redes, aliado a essa

\footnotetext{
língua, ao passo que "linguageiro" recobre o adjetivo usado para descrever fenômenos de outras linguagens. Essa distinção se tornará importante à medida que o texto avança.

${ }^{9}$ Importante a lembrança de que essa relação, "que estabelece uma correlação entre as partes de dois sistemas semióticos", "não está constatada, mas instaurada em virtude de conexões que se descobrem ou que se estabelecem entre dois sistemas distintos" (BENVENISTE, 1989, p. 62). Isso quer dizer que não se trata de uma relação que os próprios sistemas estabelecem entre si, aprioristicamente, mas depende fundamentalmente de relações estabelecidas e mantidas pelo sujeito que mobiliza os diferentes sistemas (ou que os analisa), colocando-os em relação.

${ }^{10} \mathrm{O}$ termo é inspirado em Benveniste, para quem “[n]ão captamos o pensamento a não ser já adequado aos quadros da língua" (1995, p. 69 - ênfase acrescida).

${ }^{11}$ Entendemos "enunciação na fotografia" metonimicamente, a partir da célebre definição benvenisteana em $O$ aparelho forma da enunciação, em que o autor a define como o ato de colocar "uma linguagem" (a língua, no original) em funcionamento por meio de um ato individual de utilização.
} 
passagem de eu para um ele, instaura, além da possibilidade da reprodutibilidade infinita, também um efeito de desaparecimento do sujeito, ainda que promovido pelo próprio sujeito, no que chamamos, para recorrer a um termo de Le Breton (2018), de "desaparecer de si", uma acentuada "tentação contemporânea". Resta, portanto, explicar, em termos enunciativos, essa aparente contradição, em que exposição se transforma em desaparecimento.

Para tanto, este artigo organiza-se da seguinte forma: em um primeiro momento, estabelecemos a motivação inicial do trabalho de investigação, recorrendo a outros campos do saber, na grande área de Ciências Humanas, que têm mostrado interesse na observação dos modos de ser e estar no mundo contemporâneo. Isso porque, se a Linguística tem se ocupado de descrever aspectos bastante pontuais da incorporação de mídias digitais à comunicação, as teorias de base enunciativa ainda ocupam lugar lacunar nessa reflexão. Iniciamos, assim, recorrendo ao que sociológicos, antropólogos, filósofos, psicólogos e psicanalistas têm manifestado quanto aos efeitos de dessubjetivação do sujeito contemporâneo, na expectativa de evidenciar que tal problemática vai de par com uma questão sobre a subjetividade na linguagem, tão cara ao campo enunciativo.

Isso posto, partimos para uma segunda seção, em que, preocupados justamente com a questão da subjetividade, buscamos explicitar alguns conceitos da teoria de Émile Benveniste que nos serão úteis para a proposta aqui apresentada. Investiremos, destarte, nos conceitos de interpretância da língua em relação a outros sistemas semióticos e no estatuto linguístico de pessoa e não-pessoa. Cabe aqui a observação, à guisa de satisfação de uma possível inquietação do leitor, sobre o porquê de recorrermos a uma teoria linguística para explicar um fenômeno expresso por uma materialidade não linguística (a fotográfica). A isso, respondemos que a potência do trabalho benvenisteano parece residir justamente em sua capacidade de, descrevendo a língua, podermos, por derivação e deslocamento, aplicar seu raciocínio a outras linguagens, na intenção de verificar, tal como o próprio linguista fez, o que, em outros sistemas semiológicos, funciona de forma diferente da língua. Releva ainda salientar que, em que pese pouquíssimos linguistas terem se dedicado à questão do que torna a língua um sistema particular de signos entre todas as outras manifestações semiológicas na tentativa de validar a hipótese saussuriana de que a língua é o principal desses sistemas -, é Benveniste quem postula uma resposta mais bem acabada sobre isso, ao propor a ideia de que a língua é o único sistema que opera concomitantemente por dois universos de significância.

Em seguida, passamos a uma análise de como acreditamos que a teoria benvenisteana pode lançar luz sobre o processo de produção de sentido das fotografias transparentes, notadamente os autorretratos compartilhados em rede. É importante a ressalva, embora óbvia, de que o linguista sírio nunca se debruçou sobre essa investigação, até mesmo pelo contexto temporal e espacial em que escreveu seus artigos, sendo as propostas veiculadas na terceira seção deste texto fruto inteiramente da interpretação e dos deslocamentos que fazemos dos postulados teóricos de sua obra. 


\section{A problemática do sujeito contemporâneo: reflexos pela linguagem}

Se muito já foi discutido sobre as mudanças conjunturais que marcaram a transição para a Modernidade, não menos frequentes são as investigações sobre o que seria isso a que costumamos chamar, sem muita precisão ou entendimento, de pós-modernidade, modernidade tardia, modernidade líquida, contemporaneidade ou mesmo pós-verdade. Fato é que, nesses tempos a que chamamos, por falta de melhor termo, de contemporâneos, nossa vida, como atesta Dunker (2017), está

(...) cada vez mais acelerada, icônica e funcionalizada. Nossa experiência de cidade é cada vez mais acelerada. Nossa vivência da viagem é cada vez mais icônica e exibicionista. (...) É o que alguns teóricos da linguagem chamam de cultura do connect e cut, na qual há igual facilidade de acesso e de desligamento no contato com o outro. Isso gera um estado de falas interrompidas, demandas cruzadas, palavras sem destinatário, entonações indeterminadas. (DUNKER, 2017, pos. $238^{12}$, grifos no original)

Alguns pontos merecem atenção no diagnóstico traçado pelo autor. Primeiramente, a noção de que nossa vida está mais icônica - isto é, que nossa comunicação se pauta cada vez mais por linguagens mais icônicas (imagéticas) - se coaduna com a proposta que aqui tecemos, bem como com o caráter exibicionista que pressupomos, na introdução, pela publicação e intensa circulação de tais imagens. A isso, alia-se o entendimento do autor quanto à falta de destinatário de nossas (poucas) palavras, estabelecendo o que aludiremos, mais adiante, como enunciações sem diálogo ${ }^{13}$. Isso porque a imagem é lida de uma forma completamente diferente da leitura que se realiza da palavra escrita:

(...) a diferença entre ler linhas escritas e ler uma pintura é a seguinte: precisamos seguir o texto se quisermos captar sua mensagem, enquanto na pintura podemos apreender a mensagem primeiro e depois tentar decompô-la. Essa é, então, a diferença entre a linha de uma só dimensão e a superfície de duas dimensões: uma almeja chegar a algum lugar e a outra já está lá, mas pode mostrar como lá chegou. A diferença é de tempo, e envolve o presente, o passado e o futuro. (FLUSSER, 2017, pos. 977).

As ideias de Flusser parecem se alinhar perfeitamente à ideia de caráter linear do significante, exposto no Curso de Linguística Geral (SAUSSURE, 2012). Sendo o significante, seja em seu caráter fônico, seja no modo escrito, sempre promovido à existência em uma linha unidirecional, é incontornável que seu conteúdo se revele um pouco de cada vez, até

\footnotetext{
${ }^{12}$ Os livros utilizados em versão eletrônica (Kindle) terão suas páginas referenciadas pelo sistema de posição, e não de página.

${ }^{13}$ Benveniste não utiliza este termo. Depreendemos sua possibilidade, no entanto, com base em nossa leitura de $O$ aparelho formal da enunciação, texto que o autor finaliza discutindo os limites do diálogo ao considerar, por exemplo, se a comunhão fática, a qual, aparentemente, tem estrutura de diálogo, pode efetivamente ser vista como tal. Neste artigo, partimos do pressuposto de que é possível, portanto, haver enunciações que apresentam forma de monólogo, mas que apresentam características de diálogo, bem como diálogos que se apresentam como tais em sua estrutura formal, sem que sejam, efetivamente, intersubjetivos.
} 
termos uma ideia do todo. Na imagem, ao contrário, tudo está dado de uma só vez, e a decomposição desse sentido construído na forma imagética é acessório ao entendimento da mensagem (motivo pelo qual Flusser utiliza o verbo tentar para se referir à decomposição das formas que compõe a imagem).

Tudo isso envolve, conforme a astuta observação do filósofo, uma questão de tempo, que o leva a ponderar: "é óbvio que os dois tipos de leitura envolvem tempo, mas será o 'mesmo' tempo?" (pos. 977). Ora, a questão do tempo é central na reflexão que aqui propomos por, pelo menos, dois motivos: o primeiro deles se relaciona à "vida mais acelerada", assim denominada por Dunker (2017), o que tem implicações na forma como narramos nossas vivências, tornando-as experiências, conforme desenvolvemos a seguir. 0 segundo motivo é que, ao termos, na imagem, o "tudo de uma vez", passamos a estabelecer com o tempo uma relação diferente daquela que estabelecemos com a palavra, por seu caráter linear: "demora muito mais tempo descrever por escrito o que alguém viu em uma pintura do que simplesmente vê-la" (FLUSSER, 2017, pos. 989). Dessa forma, talvez a aceleração sobre a qual escreve Dunker esteja ligada ao costume que acabamos por desenvolver em uma sociedade cuja comunicação se dá cada vez mais por imagens, uma sociedade em que "o "homem unidimensional ${ }^{14 \prime}$ está desaparecendo" (FLUSSER, 2017, pos. 955), pois que o relógio desse mesmo homem parece não conseguir mais suportar o ritmo mais lento da palavra.

Propomos, entretanto, que, em vez de desaparecer por completo - o que, provavelmente não irá acontecer -, o "homem unidimensional" esteja, talvez, atribuindo o mesmo caráter do "tudo de uma vez" da imagem à palavra, numa forma de interação muito específica. Nesse tipo particular de enunciação, temos uma diferença radical em relação à enunciação que estabelece alteridade e, consequentemente, diálogo:

Na fala, (...) estamos "amarrados" na situação, presos em um jogo de "risco" no qual as coisas devem ser decididas em "tempo real". A aceleração da experiência ataca esse aspecto da palavra, criando um tempo "irreal" em meio a uma degradação da experiência de fala apenas a uma peça de comunicação. (...) Passemos ao caráter icônico de nossa surdez (...) (DUNKER, 2017, pos. 291 - grifos nossos)

O aspecto da palavra que é atacado corresponde justamente ao caráter linear do significante, o qual institui, forçosamente, o tempo da fala como um tempo de vivência, de elaboração, faltante à imagem que tudo revela a um só golpe. Na tentativa de acelerar o tempo da palavra, e na impossibilidade radical que a língua impõe àqueles que não suportam o ritmo linear do significante, temos como resultado palavras que comportam pouca alteridade.

Assim, "caráter icônico de nossa surdez" e "degradação da experiência de fala" são formas talvez mais poéticas de se referir ao que aqui chamamos de enunciação sem diálogo, enunciação que não institui alteridade, pois que é desprovida das posições ocupadas no par

\footnotetext{
${ }^{14}$ No contexto desenvolvido pelo autor, trata-se do homem que escreve, dado que unidimensional refere-se à linha do tempo em uma única direção da escrita.
} 
reversível entre eu-tu, instauradas pela enunciação verdadeiramente linguística e intersubjetiva. Nesse sentido, o tempo "irreal", aludido pelo autor, poderia bem ser substituído por tempo do virtual (CHAUÍ, 2010), o qual instala uma radical positividade. ByongChul Han, em seu livro Sociedade da transparência, explica o termo: "na sociedade positiva, na qual as coisas, agora transformadas em mercadorias, têm de ser expostas para ser, seu valor cultual desaparece em favor de seu valor expositivo" (HAN, 2017, pos. 204, grifos no original).

Aqui temos uma delimitação importante: tratamos, neste texto, estritamente desse tipo de enunciação particular, materializada pela fotografia digital, a que Han chama de fotografia transparente, ou seja, a fotografia não investida de fins estéticos, imagem destituída de seu valor sensual (velado e, portanto, cultual) em favor de um valor exibicionista e expositivo. Esse tipo singular de enunciação nos interessa porque

(...) à fotografia transparente falta o adensamento semântico e temporal. Assim, ela não fala. (...) A fotografia de hoje, totalmente tomada pelo valor expositivo, mostra uma outra temporalidade. Está determinada pela atualidade sem negatividade, sem destino, que não admite nenhuma tensão narrativa, nenhuma dramaticidade de "romance" (HAN, 2017, pos. 232, grifos no original).

Ora, perseguindo a construção de pensamento do autor com base em nossos propósitos aqui, fica evidente o contrassenso que há em se substituir o relato linguístico por uma fotografia que não fala. Assim, parafraseando a pergunta que nos norteia, temos: quem fala numa fotografia que não fala? Como narrar a si mesmo por um mecanismo que não admite narração? Discutiremos esse ponto adiante. Por ora, interessa-nos a consideração do autor de que "[o] problema não é o aumento das imagens em si, mas a coação icônica para tornar-se imagem" (pos. 266). Isso porque, se, como bem argumenta o filósofo coreano, há uma certa recorrência irrefreável e irrefletida à linguagem icônica, num processo que, em vez de instaurar negatividade (isto é, alteridade) institui uma positividade, e considerando que "[o] excesso de positividade que hoje domina a sociedade é um indicativo de que esta foi privada de sua narratividade" (pos. 667), como pensar, então, o narrar de si mesmo por meio do recurso a esse tipo de linguagem? Não estaria o recurso a essa linguagem mais icônica, por meio de imagens que, "em sua forma de mercadoria", "organizam o laço social" (KEHL, 2009, pos. 892) justamente reorganizando a capacidade do sujeito de narrar a si mesmo, criando a "corrosão do diálogo" (DUNKER, 2017) e impondo-nos um efeito de dessubjetivação? É o que parece ter sido atestado por Kehl (2009) ao constatar que

[t]alvez a necessidade de testemunhar, por meio de fotografias ou de registro em vídeo, os chamados "bons momentos da vida" revele exatamente o empobrecimento da experiência que Benjamin atribuiu, desde o início do século XX, ao lugar hiperdimensionado que a técnica ocupa na vida moderna. Seria essa necessidade de registrar em imagens supostamente fidedignas cada momento vivido um sintoma de que a temporalidade socialmente regulada na vida contemporânea esteja encurtando a experiência subjetiva da duração? Um dos efeitos dessubjetivantes da velocidade é o empobrecimento da imaginação: o que se busca, 
no instantâneo fotográfico, é uma espécie de atestado de que a vida (...) tenha sido de fato vivida (KEHL, 2009, pos. 1973).

Nesses termos, em que pese a fotografia ser usada como o "atestado de uma vida vivida", a falta do recurso à palavra cria apenas uma sequência de vivências, nunca transformadas em experiências, segundo a distinção de Walter Benjamin $(1996)^{15}$, pois que Ihe falta o tempo de duração, próprio da palavra, como supracitado. Temos, portanto, um relato sem densidade semântica, pois o que é vivido é plotado nas imagens que circulam sem palavras ${ }^{16}$ e, consequentemente, sem narração. Eis o fundamento da crítica de Han (2017) a uma sociedade que de tal forma endossa a exposição em detrimento da narração que se torna pornográfica:

A sociedade exposta é uma sociedade pornográfica; tudo está voltado para fora, desvelado, despido, desnudo, exposto. O excesso de exposição transforma tudo em mercadoria que "está à mercê da corrosão imediata, sem qualquer mistério". (...) As imagens preenchidas pelo valor expositivo não demonstram qualquer complexidade; são univocamente claras, i. é., pornográficas. (HAN, 2017. pos. 232280)

E a pornografia, isto é, o excesso de exposição que nos faz prescindir de imaginação, posto que tudo revela, quando materializada em fotografias transparentes, tem seu custo: "[a]s imagens pornográficas, desculturalizadas, não apresentam nada que possa ser lido" (pos. 569). Ao não permitir leitura, entendemos, conforme exposição adiante, que não há processo de diálogo. Defenderemos mais detidamente esse ponto de vista em momento oportuno.

Ainda na esteira de tentativa de entendimento dessa configuração particular das gramáticas comunicativas da interação contemporânea em rede, torna-se importante pontuar em que sentido(s) a ausência de narração, marcada pelo recurso ao ícone em

\footnotetext{
15 Para Benjamin, experiência (Erfahrung em alemão) pressupõe exatamente o que o radical "fahr", relacionado ao verbo "fahren", denota: ir, guiar, conduzir. Trajetória que, para o filósofo, é feita por meio da narração dos acontecimentos vividos. O que, ao contrário, Benjamin chama de vivência (Erlebnis) é tudo aquilo que, não passando pelo crivo da ressignificação pelo simbólico, não altera o psiquismo, produzindo apenas sensações imediatas, não simbolizadas. Eis porque, para Kehl (2009), "[é] no ato da transmissão que a vivência ganha estatuto de experiência, de modo que não faz sentido, em Benjamin, a ideia de experiência individual" (pos. 1644, grifos no original). Esse é o mesmo motivo que nos leva a conjecturar que o recurso à linguagem icônica cria um efeito de dessubjetivação do sujeito, posto que ignora, a nossa ver, a transmissão, no sentido benjaminiano.

${ }^{16}$ Como já enfatizado, quando nos referimos a "imagens que circulam sem palavras", não estamos implicando que não haja narração, até mesmo por adotarmos o conceito de narrativa visual, tampouco denotando que todo o contexto que circunda o compartilhamento de fotografias não lhe dê condições de enunciação específicas, muitas vezes até mesmo literalmente circundadas de texto verbal. Ao postularmos que não existe narração nas imagens veiculadas, estamos falando da ausência de uma narração muito específica, aquela capaz de transformar vivência em experiência, no sentido benjaminiano do termo (conforme nota anterior). Ademais, consideramos válida a apreciação empreendida por Flusser (2017) sobre a diferença entre a linha (escrita) e a superfície (imagem): "embora predomine agora no mundo o pensamento expresso em superfícies, essa espécie de pensamento não é tão consciente de sua própria estrutura, assim como o é quando expresso em linhas" (pos. 955). Assim, entendemos que a escrita que por vezes acompanha e imagem, pelo caráter simbólico e arbitrário que toma emprestado da língua, é sempre um trabalho sobre o querer dizer, elemento ausente no tipo de fotografia que analisamos aqui.
} 
detrimento do verbo, "rouba" o sujeito de uma posição na linguagem que caracteriza sua enunciação e, por consequência, seu lugar no mundo como ser linguístico, social e antropológico. No âmbito dessas duas últimas esferas, é o que Paula Sibilia (2008) bem explora em seu livro $O$ show do eu: a intimidade como espetáculo: "[a] experiência vital de cada sujeito é uma narração que apenas pode ser pensada e estruturada como tal quando a linguagem a disseca e a modela ${ }^{17 \prime \prime}$ (pos. 515, tradução nossa). Entretanto, o que se tem na contemporaneidade é que

nossos relatos autobiográficos não copiam mais aqueles romances que se liam com fruição desvelada durante horas a fio. Em vez disso, nossas narrativas vitais ganharam contornos audiovisuais, inclusive multiplataforma, ou transmidiáticos; e, de modo crescente, também demandam uma interatividade imediata (SIBILIA, 2016, p. 80).

Ora, se a experiência, no sentido benjaminiano do termo, retomada por Kehl (2009) e Sibilia (2016), tem relação apenas com a narração que é contornada ${ }^{18}$ e toma corpo em linguagem, num contexto de alteridade, parece-nos inevitável a consideração de que recorrer a uma linguagem mais icônica e menos arbitrária configura um caminhar a passos largos para uma crise da narrativa sobre si mesmo para o sujeito contemporâneo. Isso porque, se a iconicidade estabelece uma relação representativa da realidade por meio de similaridade, o caráter arbitrário do signo linguístico, marcado pela falta de motivação na relação entre significante e significado, exclui totalmente a ideia de referente no mundo, operando apenas com a ideia de "conceito", motivo pelo qual a língua, conjunto de signos radicalmente arbitrários organizados em um sistema de valores puros, conforme a célebre definição saussuriana, precisa sempre ser adquirida, e sempre em um contexto social, ao contrário dos sistemas icônicos ou indiciais, os quais, para serem definidos como tais e para serem interpretados no seio social, necessitam tomar emprestado o aparato conceitual da língua. Assim, a iconicidade destitui o sujeito da necessidade de um tipo específico de processo de produção de sentido, o que redunda na falta de elaboração de sua própria vivência, a qual a transformaria em experiência por meio do eterno embate com a palavra, na tentativa de circunscrição de um sentido que nunca cessa de não se permitir tomar a "forma perfeita", mas que, justamente por isso, significa.

É por essa razão que esta seção tem o título de "reflexos pela linguagem". Primeiramente, porque a constituição do sujeito contemporâneo, marcadamente acentuada por uma sociedade sem relato, para utilizar o bonito título que Nestor Canclini dá a um de seus livros, tem reflexos no uso linguageiro que esse sujeito faz. Até aqui, tentamos argumentar que o recurso a uma linguagem mais icônica e menos arbitrária é um desses reflexos. No afã

\footnotetext{
${ }^{17}$ O texto original em espanhol (2008) foi utilizado aqui, pois acreditamos que apresenta mais claramente a ideia que tentamos desenvolver. Na tradução brasileira, revista pela autora, a passagem é lida, à página 59 , da seguinte forma: "A experiência vital de cada sujeito é um relato que só pode ser pensado e estruturado como tal se, de algum modo, for cristalizado na linguagem".

18 No duplo sentido do termo, de ganhar contornos delimitáveis e de superar uma dificuldade, nesse caso, a própria dificuldade de não se poder tudo dizer (cf. Introdução).
} 
de estar no mesmo passo apressado da sociedade que institui a contagem do tempo como uma de suas principais marcas (KEHL, 2009), o sujeito recorre a um tipo de linguagem específico, que dá tudo a ver de uma só vez, sem a necessidade do "uma palavra de cada vez" da enunciação linguística. Eis um traço específico não só dos enunciados (isto é, dos textos produzidos) como também das enunciações (isto é, do ato mesmo de produzir enunciados) em tempos de pós-verdade:

O segundo traço da pós-verdade é que sua retórica é icônica. Cada vez mais lemos a mensagem que o outro nos envia em pacotes de informação, compostos por imagens e textos, que se apresentam como um "todo de uma vez". Isso degrada a narrativa da viagem a um percurso sem memória (DUNKER, 2017, pos. 247, grifo no original)

Ainda que o autor se refira especificamente aos registros fotográficos de viagens, acreditamos ser possível, como defendido até aqui, que tal forma de enunciação (icônica) esteja também afetando nossa própria subjetividade como efeito de uma transformação em nossa forma de narrarmos a nós mesmo. É tempo, então, de justificar uma segunda acepção do título desta seção.

\section{Da subjetividade na linguagem ao efeito do desaparecer de si}

"Reflexos pela linguagem" diz respeito também ao fato de ser "na linguagem e pela linguagem que o homem se constitui como sujeito, porque só a linguagem fundamenta na realidade, na sua realidade que é a do ser, o conceito de 'ego'" (BENVENISTE, 1995, p. 286). Em outras palavras, é na emergência da capacidade simbólica, balizada pelo acesso à linguagem, que podemos dizer que o ser humano deixa de ser homem, categoria biológica, para se tornar sujeito, categoria antropológica, pois o ser humano não é mais um animal restrito à sua condição biológica. Nas palavras de Flusser (2017), "o homem é um animal não natural", uma vez que "se comunica com outros homens por meio de artifícios" (pos. 805), e isso cria, para o ser humano, uma segunda natureza. É pelo simbólico, no sentido de Cassirer (2001; 2012), cuja expressão máxima é a linguagem, que o homem se torna ser humano. 0 homem, assim, só pode ser sujeito em virtude de sua condição de falante, que o instaura no campo das formas simbólicas.

É no conjunto dessas formas simbólicas, as quais não se reduzem à linguagem, mas que encontram nela sua maior expressão, que o homem cria o reflexo de quem é e pode, então, constituir essa unidade fictícia a que chamamos de identidade. Uma vez que "[o] sentimento de identidade é o lugar sempre em movimento em que o indivíduo experimenta sua singularidade e sua diferença" (LE BRETON, 2018, pos. 2679), podemos compreender melhor a afirmação de Benveniste de que "a consciência de si mesmo só é possível se experimentada por contraste" (p. 286), ou seja, que é no exercício linguístico de alteridade ("movimento", nos termos de Le Breton) que o homem reconhece a si mesmo, pela diferença com o outro. Eu me torno eu porque não sou um outro, não sou um tu. 
A banalidade de tal afirmação não revela, na verdade, a profundidade da reflexão de Benveniste. Ao afirmar que "a subjetividade (...) é a emergência no ser de uma propriedade fundamental da linguagem" (p. 286), o linguista realça um fator de suma importância: "o fundamento da 'subjetividade' (...) se determina pelo status linguístico da 'pessoa'"' (idem). Nas belas palavras de Paula Siblilia (2016, p. 58), que não cita Benveniste, mas parece claramente investida de seu espírito,

[a] experiência de si como um eu se deve, em primeiro lugar, à condição de narrador do sujeito: alguém que é capaz de organizar a sua experiência na primeira pessoa do singular. Mas este não se expressa unívoca e linearmente através de suas palavras, traduzindo em texto alguma entidade que precederia o relato e que, por tal motivo, seria mais real ou verdadeira do que a mera história contada. Em vez disso, cabe admitir que a subjetividade se constitui na vertigem desse córrego discursivo, pois é nesse fluxo narrativo que o eu de fato se realiza (SIBILIA, 2016, p. 58 - grifos no original).

No contexto do que tratamos aqui, temos uma notável implicação: se a subjetividade é essa espécie de "subproduto" do próprio ato de adquirir linguagem, uma vez que, entrando na esfera simbólica, o homem passa a ser sujeito, pois que ocupa o lugar linguístico de eu, como essa instauração e constituição de subjetividade se dá quando a linguagem que está em jogo é a fotografia? Em outras palavras, se a fotografia transparente não fala, qual o lugar de eu? É possível pensar a subjetividade numa expressão linguageira icônica, em que não temos "o primeiro ponto de apoio para a revelação da subjetividade" (BENVENISTE, 1995, p. 288), a saber, os pronomes?

As discussões da primeira parte deste artigo já nos permitem encaminhar a conclusão preliminar de que há algo que se altera nessa dinâmica comunicativa e no próprio sujeito quando a linguagem mobilizada não é a língua. Antes de ensaiarmos, porém, uma resposta mais ancorada nos termos da Linguística, é necessário enfatizar alguns pontos do pensamento benvenisteano sobre a subjetividade na linguagem.

Para o linguista sírio, há uma série de "signos móveis" (os pronomes e toda a série dêitica) que marcam uma diferença entre a "linguagem como sistema de signos e a linguagem assumida como exercício pelo indivíduo" (1995, p. 281). No primeiro caso, temos o estudo da língua em seu caráter estritamente intrassistêmico, no âmbito daquilo a que Saussure chamou de langue. No segundo, aquilo de que a Enunciação se ocupa: a língua posta em funcionamento por um ato individual de utilização ${ }^{19}$. É por este último aspecto que nos interessamos, mais precisamente pelas particularidades da organização linguística da categoria de pessoa, desenvolvida por Benveniste principalmente nos textos Estrutura das relações de pessoa no verbo, A natureza dos pronomes e Da subjetividade na linguagem ${ }^{20}$,

\footnotetext{
${ }^{19}$ Isso tem implicações profundas na obra de Benveniste, que pode bem ser resumido por um trecho de um de seus últimos textos (O aparelho formal da enunciação), de 1970: "as condições de emprego das formas não são, em nosso modo de entender, idênticas às condições de emprego da língua" (1989, p. 81).

${ }^{20}$ É importante observar que os três principais textos que versam sobre as particularidades dos pronomes no conjunto da reflexão de Benveniste foram um escrito em 1946 (Estrutura das relações de pessoa no verbo) e os
} 
artigos que compõem, não por acaso, a seção do livro Problemas de Linguística Geral I intitulada $O$ homem na língua.

Para Benveniste, e esta é a noção que mais nos interessa aqui, todas as línguas humanas comportam uma tríade de pessoas: $e u$, elemento que enuncia; $t u$, elemento a quem se enuncia; e ele, elemento sobre o qual se enuncia. Nessa organização, temos uma "disparidade entre a terceira pessoa e as duas primeiras" (1995, p. 250), marcada por dois tipos de relação que se impõem: primeiramente, entre "eu" e "tu" há uma correlação de personalidade 21 , que falta em "ele". Ou seja, apenas "eu" e "tu" podem, efetivamente, serem denominadas "pessoa", uma vez que "ele", a dita "terceira pessoa", "não é uma 'pessoa'; é inclusive a forma verbal que tem por função exprimir a 'não-pessoa'” (1995, p. 251). Deixemos que o próprio Benveniste desenvolva melhor essa questão:

\begin{abstract}
Nas duas primeiras pessoas, há ao mesmo tempo uma pessoa implicada e um discurso sobre essa pessoa. Eu designa aquele que fala e implica ao mesmo tempo um enunciado sobre o "eu": dizendo eu, não posso deixar de falar de mim. Na segunda pessoa, "tu" é necessariamente designado por "eu" e não pode ser pensado fora de uma situação a partir do "eu"; e, ao mesmo tempo, eu enuncia algo como um predicado de "tu". Da terceira pessoa, porém, um predicado é bem enunciado somente fora do "eu-tu". (...) A forma dita de terceira pessoa comporta realmente uma indicação de enunciado sobre alguém ou alguma coisa, mas não referida a uma "pessoa" específica. O elemento variável e propriamente "pessoal" dessas denominações falta aqui (BENVENISTE, 1995, p. 250, grifos no original).
\end{abstract}

Temos, então, que "a pessoa só é própria às posições 'eu' e 'tu'. A terceira pessoa é, em virtude da sua própria estrutura, a forma não pessoal da flexão verbal. De fato, serve sempre quando a pessoa não é designada e principalmente na expressão dita impessoal" (1995, p. 252).

Uma segunda relação se estabelece, dessa vez diferenciando o par "eu" e "tu". Ao primeiro, imputa-se a noção de pessoa subjetiva; ao segundo, de pessoa não subjetiva. Ambas as características fundam o que Benveniste chama de correlação de subjetividade.

Nesse quadro figurativo, tem-se, portanto, que a enunciação é um "colocar a língua em funcionamento por um ato individual de utilização" (BENVENISTE, 1989, p. 82) e que "a relação do locutor com a língua determina os caracteres linguísticos da enunciação" (idem). Importante frisar, entretanto, que esse colocar a língua em funcionamento só ocorre na condição de presença de dois fatores: 1) de o locutor se "apresenta[r] como sujeito,

outros dois (A Natureza dos pronomes e Da subjetividade na linguagem) na década de 50. Isso significa que a teorização sobre esse aspecto linguístico particular ocorre em um momento relativamente "cedo" de sua teoria, posto que em seus textos publicados mais tardiamente, no final da década de 60 e início da década de 70, temos uma teoria bem menos centralizada em marcadores específicos de pessoa, tempo e espaço e mais ancorada na ideia de que a língua toda se apresenta como um conjunto de formas (o aparelho formal da língua) que, agenciadas de maneira particular, inserem aquele que fala em sua fala (pela emergência de um aparelho formal da enunciação). Entretanto, acreditamos que as reflexões produzidas por Benveniste nas décadas de 40 e 50 , ainda que pareçam tomar outra forma ao longo da teorização do autor, não se encontram invalidadas em nenhum momento de sua teoria.

${ }^{21}$ Talvez uma tradução melhor fosse pelo termo "pessoalidade", uma vez que a noção implica o caráter de pessoa, não de personalidade. 
remetendo a ele mesmo como eu no seu discurso" (1995, p. 286); e 2) que esse sujeito, "desde que ele se declar[e] locutor e assum[a] a língua, implant[e] o outro diante de si, qualquer que seja o grau de presença que ele atribua a este outro" (1989, p. 84, grifo no original). Disso, deriva-se, portanto, igual e simetricamente, dois aspectos: 1) que "é verdade ao pé da letra que o funcionamento da subjetividade está no exercício da língua" (1995, p. 288); e 2) que a intersubjetividade é a condição para a subjetividade, pois que "é numa realidade dialética que englobe os dois termos ["eu" e "tu"] e os defina pela relação mútua que se descobre o fundamento linguístico da subjetividade" (p. 287).

Seguindo, pois, em nossa linha de raciocínio, entendemos, ainda com Benveniste, que, se todas as línguas humanas apresentam as formas pronominais e as funções por elas desempenhadas, é porque "o problema dos pronomes é ao mesmo tempo um problema de linguagem e um problema de línguas, ou melhor, que só é um problema de línguas por ser, em primeiro lugar, um problema de linguagem" (1995, p. 277). Se assim for, parece-nos lícito pensar que linguagem, ainda que empregada por Benveniste provavelmente para se referir à faculdade da linguagem, no sentido saussuriano do termo, pode, talvez, num deslocamento teórico, se aproximar ao que Cassirer $(2001 ; 2012)$ chama de formas simbólicas ${ }^{22}$. Se assim o for, é possível conjecturar, então, que diferentes formas simbólicas apresentam, cada uma à sua forma, funções que estabelecem correlatos à função pronominal. Isto é, cada linguagem deveria permitir, de alguma forma, que o sujeito, ao mobilizar aquela linguagem, instale-se como locutor. Certamente, como Benveniste mesmo apresenta em seu complexo artigo Semiologia da língua, não há dúvidas de que as formas linguísticas de expressão de subjetividade são, de longe, as mais ricas e mais complexas entre as linguagens. Não à toa a língua é o interpretante de todos os outros sistemas semiológicos, inclusive dela mesma, pois "nenhuma semiologia do som, da cor, da imagem será formulada em sons, em cores, em imagens", razão pela qual "toda semiologia de um sistema não-linguístico deve pedir emprestada a interpretação da língua, não pode existir senão pela e na semiologia da língua" (1989, p. 61).

Tentemos desenvolver, agora, as implicações que a organização da categoria de pessoa e o caráter de interpretância da língua em relação aos outros sistemas semiológicos têm frente a nosso problema de pesquisa.

\section{Implicações}

Comecemos pela questão do caráter de interpretância da língua. Sem nos atermos à complexa discussão desenvolvida por Benveniste em Semiologia da língua, cuja repercussão para o terreno dos estudos de linguagens ainda está por ser feita, podemos postular que a ideia desenvolvida pelo autor a respeito de "a língua ocupa[r] uma situação particular no universo dos sistemas de signos" (1989, p. 55) parece estar em consonância com a reflexão que desenvolvemos na primeira parte deste artigo. Ao ressaltarmos, recorrendo a autores de

\footnotetext{
${ }^{22}$ Nesse caso, teríamos que usar o termo linguagens, no plural.
} 
outros campos das ciências humanas, a importância da linguagem para a formação do sujeito social e para a narração de si, chamamos atenção para o fato de que apenas por meio do recurso linguístico, isto é, verbal, é que se torna possível uma narração verdadeiramente subjetiva e transformativa. Isso porque é próprio às línguas humanas apresentarem lugar cativo a "eu" e "tu". Designar-se como "eu", como vimos, é implantar diante de si um "tu", num processo em que um se torna o correlato dialético de outro. Ora, conforme afirmamos, é possível que outras linguagens também disponham de formas pelas quais o sujeito possa delas se apropriar para enunciar-se de forma não verbal. A questão é que apenas a língua parece tornar esse movimento de apropriação e implantação do outro de si um fato incontornável, sobre o qual repousa a vida mesmo da linguagem no seio social. Falamos porque a língua nos permite ocupar a posição de "eu" (linguisticamente expresso ou não, é sempre importante lembrar, pois se trata mais de uma posição na linguagem do que de uma categoria linguística) e, ao fazer isso, implantar "automaticamente" um alocutário à minha enunciação.

Como isso se passa, então, em outras linguagens? Esse trabalho ainda está por ser feito e não corresponde a nossos objetivos aqui. Entretanto, podemos, de forma mais recortada, indagar-nos: como a fotografia institui a subjetividade? Um dos aspectos certamente se dá pela convocação do olhar. Contudo, há que se traçar uma linha que separe aquilo que Han chama de fotografia transparente, nosso objeto aqui, da fotografia com fins estéticos, da qual não nos ocupamos. Nossa hipótese é de que a dita fotografia transparente não instaura lugar de subjetividade.

Decerto, não podemos esquecer que há um lugar para o sujeito no instante mesmo em que a fotografia é produzida. No entanto, essa problemática ganha contornos mais interessantes quando analisamos o caso das selfies. Temos, nesse caso em particular, o gesto de fotografar que permite ao fotógrafo se instalar como eu, ao fazer escolhas quanto a que elementos aparecerão na fotografia ou não. É o momento análogo à enunciação, ao colocar a língua em funcionamento. Contudo, chamamos atenção para um aspecto particular desse tipo de enunciado, agora pensando no produto produzido, isto é, a fotografia: não estaria o indivíduo fotografado, que, por acaso, coincide com o sujeito fotógrafo, colocando-se no produto dessa enunciação (na fotografia) como um "ele", ou seja, não só como pessoa que fala, mas também como elemento do qual se fala? Pensemos mais sobre isso.

Conforme depreendemos das palavras de Benveniste, não há como falar de mim sem recorrer à posição enunciativa denotada pelo pronome eu e, ao fazê-lo, a marca que resta no enunciado é sempre do paradigma do eu. É por isso que Benveniste afirma que se colocar como eu instaura um duplo fenômeno: temos uma pessoa implicada e um discurso sobre essa pessoa. Mesmo que, na enunciação verbal, predicados possam ser feitos sobre eu, na enunciação, eu jamais torna-se ele. É impossível, linguisticamente falando, tratarmos a nós mesmos como ele em nosso próprio discurso, a não ser, evidentemente, em casos de configurações psíquicas específicas ou pela licença literária ${ }^{23}$. E, ao ocuparmos o lugar

\footnotetext{
${ }^{23}$ Esse é um aspecto, inclusive, que organiza a correlação de pessoa subjetiva, para "eu", e pessoa não subjetiva,
} 
linguístico de "eu", nos constituímos como eu, pois predicar sobre eu implica sempre manter a posição de eu na linguagem. Nenhum correlato disso parece ocorrer em outras linguagens. Eis porque é possível, em uma fotografia de si mesmo, tornar-se ícone: trata-se não mais de um eu, mas de um ele, termo sobre o qual se fala. É por isso também que, sendo "ele" a única "pessoa" do discurso sobre a qual se permite a pluralidade ${ }^{24}$, vemos o fenômeno da multiplicação infindável de fotografias de mesmo tipo, sem espessura semântica, como no vídeo citado no início deste texto. A reprodutibilidade técnica, nesse caso, é precisamente o que permite a criação do que Han (2015) chama de "tirania do igual".

Se essa argumentação for válida, como pensamos, é possível a partir daí explicar duas afirmações que fizemos no início deste texto: 1) a de que esse tipo específico de fotografia é uma enunciação sem diálogo; e 2) a de que a iconicidade coloca o sujeito em uma outra relação com sua subjetividade. Analisemos cada aspecto.

Por que consideramos a fotografia uma enunciação? Porque, de fato, temos um sujeito que, pelo ato mesmo de fotografar, põe em marcha uma linguagem específica. Isso seria o análogo do que Benveniste chama de "colocar a língua em funcionamento por um ato individual de utilização". Evidentemente, há uma diferença fundamental nos dois casos: a interferência do meio técnico. Se, para a enunciação verbal, não é necessário qualquer tipo de técnica, posto que a linguagem é adquirida sem qualquer esforço por qualquer falante em condições normais, é talvez possível pensar que o intermediário técnico (a máquina fotográfica, o aparato necessário para o compartilhamento da fotografia etc.) seja precisamente o elemento que faculte ao sujeito esse apropriar-se da linguagem fotográfica. Entretanto, isso tem um preço: como afirmaria Flusser (2011), tornamo-nos funcionários da caixa-preta. Transpondo o conceito do pensador tcheco para o contexto desenvolvido aqui, poderíamos conjecturar que a mediação do meio técnico tem como ônus, para o sujeito, o efeito da dessubjetivação. Eis porque a língua, única que prescinde de intermediário técnico entre as linguagens, é o mais complexo entre os sistemas semióticos. Eis também, talvez, o porquê de Benveniste pontuar que "seria preciso também distinguir a enunciação falada da enunciação escrita" (1989, p. 90), posto que a escrita é uma tecnologia. Tem-se, aí, um intricado campo de discussão, que anunciamos na introdução deste texto sob o rótulo da criação de novas formas de subjetivação a partir dos meios técnicos de comunicação.

Há algo, porém, que Benveniste já nos ensinava, sem nunca ter refletido acerca do

para "tu". Observe-se que não há essa impossibilidade de "tu" tornar-se "ele" e ser predicado. É o que acontece, por exemplo, nas formas de polidez que recorrem a formas de terceira pessoa, como "vossa majestade", que, embora tenham sentido de segunda pessoa, são formalmente uma terceira. Isso se deve ao caráter de dissimetria que há entre "eu" e "tu": uma vez que "eu" é sempre transcendente ao "tu", em casos em que se torna necessário estabelecer o "tu" como elemento mais importante do diálogo, como nesses casos de polidez, transforma-se esse "tu" em "ele", como um recurso que visa a "institucionalizar" o alocutário, colocando-o em uma aparente transcendência em relação a "eu".

${ }^{24}$ Benveniste reconhece, evidentemente, que há o que chamamos de primeira e segunda pessoas do plural (nós e vós, respectivamente). Entretanto, para o autor, "nós" não é um conjunto de "eus", mas o que ele chama de "pessoa amplificada". Nós refere-se sempre a "eu e mais alguém", que pode ser "eu e tu", "eu e ele", "eu, tu e ele", mas jamais "eu e eu". Ideia análoga é vista em relação a "tu". Assim, somente o termo "ele" permite o verdadeiro plural: "eles". 
meio técnico: somente a língua é interpretante dos outros sistemas semiológicos. Encontramos aí o fundamento do segundo ponto que gostaríamos de desenvolver. Afirmamos que a fotografia parece instaurar um efeito de dessubjetivação do sujeito por dois motivos: primeiro, por ser mediada pelo caráter técnico; segundo, porque falamos de um tipo de fotografia muito específico, aquele a que Han chamou de fotografia transparente. Isso porque, nesse tipo de fotografia, de valor expositivo, de caráter pornográfico, temos ausência de narração. Em termos benvenisteanos, temos uma linguagem, a fotográfica, que, para transformar vivências em experiências, precisa "pedir emprestada a interpretação da língua". De fato, talvez resida aí uma das diferenças entre a fotografia transparente e a fotografia com fins estéticos: o recurso a um elemento verbal que cria a narração. Basta lembrarmos, por exemplo, que Taryn Simon, artista plástica estadunidense, ao discutir os textos que acompanham as fotografias de seu trabalho Um Índice Americano do Escondido e Estranho, destaca:

\begin{abstract}
Cada imagem contém um texto com fatos bem detalhados. E o que mais me interessa é o espaço invisível entre um texto e a sua respectiva imagem, e como a imagem é transformada pelo texto, e o texto pela imagem. Na melhor das hipóteses, a imagem deveria flutuar em abstração e múltiplas verdades e fantasia. E então $o$ texto funciona como esta âncora cruel, aquele tipo que prega no chão (SIMON, 2009).
\end{abstract}

A descrição de Simon sobre seu processo de exposição de fotografias revela-nos a flagrante dissonância que há entre um projeto fotográfico e a fotografia transparente: o grau de engajamento em uma narrativa visual. Simon parece reconhecer, pelos elementos que destacamos em sua fala, que o texto verbal dá outra significância à imagem, e que é precisamente no intervalo entre texto e imagem que o sentido se cria, numa imagem que só ganha sentido pela semiologia que toma emprestada da língua. É a esse tipo de relação a que aludíamos quando falávamos de narração. É esse tipo de dinâmica entre texto e imagem que parece faltar às fotografias transparentes.

Tomando esses princípios como verdadeiros, chegamos, então, finalmente, ao cerne daquilo a que chamamos de efeito de dessubjetivação do sujeito. Entendemos esse aspecto em duas vias: primeiramente, pela possibilidade única, impossível na enunciação verbal, de o "eu" ocupar, concomitantemente, o lugar de "ele". Em um segundo plano, derivado do primeiro, pelo fato de que, ao ocupar a posição de "ele", o locutor deixa sua posição subjetiva, marcada pela posição de "eu", e passa a ocupar o lugar de uma "não-pessoa"25. É como resultado desse deslizamento de uma posição para a outra que passamos a observar o fenômeno de uma

sociabilidade líquida ou a cultura somática de nosso tempo, delineando um tipo de eu mais epidérmico e flexível, que se exibe na superfície da pele e das telas. Referemse também às personalidades alterdirigidas e não mais introdirigidas, construções

\footnotetext{
${ }^{25}$ Se esse raciocínio estiver correto, temos, então, que outras linguagens podem alterar, de alguma forma, o esquema canônico do famoso quadro figurativo benvenisteano de eu-tu-aqui-agora. Investigar essa questão não é nosso objetivo aqui, mas merece atenção em futuros trabalhos.
} 
de si orientadas para o olhar alheio ou "exteriorizadas", não mais introspectivas nem intimistas (SIBILIA, 2016, p. 48 - grifos no original).

Observe-se que, em termos do que temos tentado argumentar aqui, esse "eu mais epidérmico" pode ser lido como um "eu" que, ao narrar-se por meio do recurso à fotografia e deixando o verbal à margem, destitui-se da posição subjetiva própria do exercício linguístico, tornando-se imagem. É também na passagem de "eu" para "ele", possibilitada por essa linguagem específica, que temos a emergência de uma "personalidade alterdirigida", pois que se dirige para fora da posição de pessoa subjetiva.

Podemos ainda pensar, tomando emprestado o raciocínio que Le Breton (2018) desenvolve para outros fins, que "[o indivíduo] desliza da pessoa para a persona, isto é, segundo a etimologia latina, para a máscara, sem ninguém para encarná-la e dar-lhe um rosto. Atrás dela não há mais nada. Não existe mais ninguém" (pos. 256, grifo no original). É precisamente nesse sentido que entendemos o efeito de dessubjetivação do sujeito: ao tornar-se "ele" em sua própria enunciação, fenômeno impossível do ponto de vista de uma enunciação linguística, o indivíduo (não mais sujeito) cria não um efeito de pessoa, mas de persona, de algo que não é mais eu, e sim ele, a não-pessoa. Talvez esse tipo de recurso à persona configure o que Le Breton chamou de "desaparecer de si", definido como "desistência progressiva de presença no mundo" (2018, pos. 2040), que exige do sujeito uma outra forma de ser e estar no mundo, uma nova subjetividade, isto é, um novo recurso para narração de si, que ele não consegue mais encontrar nos contornos da língua.

Esse tipo de relato fotográfico, assim, mostra o indivíduo, mas não diz do sujeito. Acima de tudo, revela nosso fracasso como seres simbólicos, posto que nunca atingimos o (justamente por isso) ilusório sentido perfeito. O recurso a uma linguagem icônica cobra um preço, como vimos, mas talvez o maior valor a pagar seja justamente o de não jogar mais o jogo das palavras que Marlene Teixeira definiu tão bem:

\footnotetext{
Os poetas sempre souberam da rebeldia da palavra, de sua "resistência" em colocarse sob o domínio daquele que a utiliza: ela diz mais ou diz menos, diz outra coisa; ela não cessa de produzir sentidos através do tempo, sentidos esses nunca acabados, jamais detidos. Se, de um lado, não se pode realizar uma fala "satisfatória", de outro, a palavra "justa" insiste em se dizer e é para encontrá-la que seguimos falando (TEIXEIRA, 2005, p. 15).
}

Cassirer tem razão ao se referir aos humanos como animais simbólicos antes de animais racionais. Apenas esqueceu de comentar, talvez por prudência, desinteresse ou intolerância ao calcanhar de Aquiles de nossa espécie, que somos também animais que fracassamos na linguagem. $O$ recurso a outros sistemas simbólicos é prova disso.

\section{Referências}

BENJAMIN, Walter. O narrador. Considerações sobre a obra de Nikolai Leskov. In: BENJAMIN, 
Walter. Obras escolhidas: magia e técnicas, arte e política. 3. ed. São Paulo: Editora Brasiliense, 1996. p. $197-221$

BENVENISTE, Émile. Problemas de Linguística Geral I. São Paulo: Pontes, 1995.

BENVENISTE, Émile. Problemas de Linguística Geral II. São Paulo: Pontes, 1989.

CASSIRER, Ernst. Ensaio sobre o homem. São Paulo: Martins Fontes, 2012.

CASSIRER, Ernst. A filosofia das formas simbólicas: a linguagem. São Paulo: Martins Fontes, 2001.

CHAUÍ, Marilena. Espaço, tempo e mundo virtual. Café Filosófico. Gravado em 02/09/2010. Disponível em: <http://www.institutocpfl.org.br/2010/09/03/cafe-filosofico-cpflespecial-\%E2\%80\%93-a-contracao-do-tempo-e-o-espaco-do-espetaculo-\%E2\%80\%93-

marilena-chaui-e-olgaria-matos/>. Acesso em: 02/08/2020

DUNKER, Christian. Subjetividade em tempos de pós-verdade. In: DUNKER, Christian et al. Ética e pós-verdade. Porto Alegre: Editora Dublinense, 2017. p. 4-34

FLUSSER, Vilém. O mundo codificado: por uma filosofia do design e da comunicação. São Paulo: UBU Editora.

FLUSSER, Vilém. Filosofia da caixa preta: ensaios para uma futura filosofia da fotografia. São Paulo: Annablume, 2011.

HAN, Byung-Chul. Sociedade da transparência. Petrópolis: Editora Vozes, 2017.

HAN, Byung-Chul. Sociedade do cansaço. Petrópolis: Editora Vozes, 2015.

KEHL, Maria Rita. O tempo e o cão: a atualidade das depressões. São Paulo: Boitempo Editorial, 2009.

LE BRETON, David. Desaparecer de si: uma tentação contemporânea. Petrópolis: Vozes, 2018.

POE, Marshall T. A history of communications: media and society from the evolution of speech to the internet. Cambridge: Cambridge University Press, 2011.

SAUSSURE, Ferdinand de. Curso de Linguística Geral. 27 ed. São Paulo: Cultrix, 2012.

SIBILIA, Paula. O show do eu: a intimidade como espetáculo. 2. ed. Rio de Janeiro: Contraponto, 2016.

SIBILIA, Paula. La intimidad como espetáculo. Buenos Aires: Fondo de Cultura Económica, 2008.

SIMON, Taryn. Taryn Simon: Photographs of secret sites. TED Talk, 2009. Disponível em: https://www.ted.com/talks/taryn simon photographs secret sites. Acesso em: 02/08/2020

STAM, Robert. Introdução à teoria do cinema. Campinas: Papirus, 2003.

TEIXEIRA, Marlene. Análise de discurso e psicanálise: elementos para uma abordagem do sentido no discurso. Porto Alegre: EDIPUCRS, 2005.

WITTGENSTEIN, Ludwig. Tractatus Logico-Philosophicus. 3. ed. São Paulo: EESC, 2008. 